\title{
Diversity Studies in Yellow Pericarp Sorghum [Sorghum bicolor (L.) Moench] Genotypes for Yield Attributes
}

\author{
B. V. Vara Prasad* and V. Sridhar
}

Department of GPBR, College of agriculture, PJTSAU, Rajendranagar, Hyderabad-30, India

*Corresponding author

\section{A B S T R A C T}

Keywords

Sorghum, Diversity, Yield

Article Info

Accepted:

04 November 2019

Available Online:

10 December 2019
An experiment was conducted at ARS, Madhira during early rabi 2016 with 40 yellow pericarp sorghum genotypes obtained from ICRISAT for diversity analysis. The genotypes were grouped into three clusters based on their similar performance of the trait under study. Plant height contributed the maximum $(54.74 \%)$ towards genetic diversity followed by leaf length (29.23\%), straw weight (7.56\%) and 100 seed weight (5.90\%). Ear length $(1.15 \%)$, grain yield per plant $(0.90 \%)$, number of leaves per plant $(0.26 \%)$, days to $50 \%$ flowering and days to maturity $(0.13 \%)$ were the other traits contributing for genetic divergence.

\section{Introduction}

Sorghum is ranked the fifth most produced food crop in the world, and it is a dietary staple for over half a billion people in over thirty countries, most of them being developing countries.

It is well adapted to the range of environmental conditions with high variability. Sorghum is the single most important cereal in the lowland areas because of its extreme resistance to water stress. Sorghum bicolor contains both cultivated and wild relative races, and it provides a substantial amount of genetic diversity for traits of agronomic importance so as to develop the crop's different variety of interest for plant breeders.

Having a good knowledge of the genetic diversity of a crop often enables the plant geneticist to select the desirable family for the breeding programme and gene introgression from distantly related germplasm. The more variable genotypes or accessions can be crossed to produce better varieties that can tolerate a range of environmental changes to abiotic and biotic stresses. Therefore, a better understanding of the genetic diversity in sorghum crop species will definitely facilitate the further improvement of this cereal crop 
concerning its genetic architecture. The genetic variability of cultivated crops and their wild relatives together form a potential and continued source for breeding new and better crop varieties. A better understanding of the genetic diversity in sorghum would greatly contribute to crop improvement with a view to food quality and other important agronomic traits. Therefore, there is a need to evaluate the available accessions for genetic diversity and identify the best accessions according to their performance.

\section{Materials and Methods}

The experiment was conducted at ARS, Madhira during early rabi 2016 with 40 yellow pericarp sorghum genotypes obtained from ICRISAT. The research design used was augmented design with no replication among the sorghum accessions, except for the two standard checks replicated in every block.

The sorghum genotypes were planted in two rows with a spacing of $45 \mathrm{~cm} \times 15 \mathrm{~cm}$ between and within rows respectively, with a row length of $5 \mathrm{~m}$. DAP, Urea, and other management practices were applied as per recommended packages for the experimental site. The data was collected on ten traits as per the recommended procedure and was subjected to statistical analysis following $\mathrm{D}^{2}$ statistics as developed by Mahalanobis (1928).

\section{Results and Discussion}

The analysis of variances revealed significant genetic diversity among the accessions of sorghum for all characters studied. Principal component analysis was performed in order to reduce a large set of phenotypic traits to a more meaningful smaller set of traits and to know which trait is contributing to maximum variability, because genetic improvement depends on the magnitude of genetic variation.

\section{Principal component analysis}

The four principal components (PCs) explained about $97 \%$ of the total variation among accessions for all traits (Table 1). The first principal component (Fig 1) obtained was $63.49 \%$ of total variance and had high contributing factor loading from plant height, which was the most important contributing trait for the relative magnitudes of eigen vectors for the first principal component, while the second principal component had high contributing factor loading from leaf length, which was $18.63 \%$; thirdly, it had a high contributing factor loading from 100 seed weight for the third principal component (10.96\%), and, finally, it had a high contributing factor loading from ear length for the fourth principal component (4.02\%). Similar results were also reported by Ganesamurthy et al., 2010 and Jain and Patel (2016).

\section{Cluster analysis}

The results of cluster analysis indicated that all the 40 sorghum genotypes were grouped into three clusters (Fig 2) based on their similar performance of the trait under study. Cluster 1 had 32 genotypes followed by cluster 2 with 7 and cluster 3 with 1 genotype. The clustering pattern indicated the existence of a considerable amount of variability among the sorghum genotypes. The inter cluster distance ranged from 23.73 to 24.99 between second and third clusters (Table 2). The mean values for the genotypes belonging to different clusters are presented in Table 3. 
Table.1 Principal component analysis in ICRISAT sorghum lines for ten traits

\begin{tabular}{|c|c|c|c|c|c|}
\hline & & $\mathbf{1 ~ V e c t o r}$ & $\mathbf{2}$ Vector & $\mathbf{3 ~ V e c t o r}$ & $\mathbf{4}$ Vector \\
\hline & Eigene value (Root) & $\mathbf{4 0 7 1 . 8 7 3 0 0}$ & $\mathbf{1 1 9 5 . 1 4 8 0 0}$ & $\mathbf{7 0 2 . 9 5 4 6 0}$ & $\mathbf{2 5 8 . 2 7 5 1 0}$ \\
\hline & \% Var. Exp. & $\mathbf{6 3 . 4 9 7 3 4}$ & $\mathbf{1 8 . 6 3 7 3 0}$ & $\mathbf{1 0 . 9 6 1 9 7}$ & $\mathbf{4 . 0 2 7 5 8}$ \\
\hline & Cum. Var. Exp. & $\mathbf{6 3 . 4 9 7 3 4}$ & $\mathbf{8 2 . 1 3 4 6 5}$ & $\mathbf{9 3 . 0 9 6 6 2}$ & $\mathbf{9 7 . 1 2 4 2 0}$ \\
\hline $\mathbf{1}$ & Plant height & 0.94307 & 0.18025 & 0.00351 & 0.03988 \\
\hline $\mathbf{2}$ & $\begin{array}{c}\text { Days to 50\% } \\
\text { flowering }\end{array}$ & -0.02780 & 0.07300 & -0.01404 & -0.06360 \\
\hline $\mathbf{3}$ & Days to maturity & -0.06899 & -0.00714 & -0.02067 & 0.00610 \\
\hline $\mathbf{4}$ & No. of leaves per & 0.01857 & 0.06224 & 0.01473 & -0.02139 \\
\hline $\mathbf{5}$ & plant & & & & \\
\hline $\mathbf{6}$ & Leaf length & -0.15085 & 0.94166 & -0.17931 & -0.18595 \\
\hline $\mathbf{7}$ & Leaf width & -0.12559 & 0.01183 & -0.01216 & -0.03812 \\
\hline $\mathbf{8}$ & Ear length & -0.08886 & 0.10326 & -0.04020 & 0.11518 \\
\hline $\mathbf{9}$ & Straw weight & 0.04592 & -0.23122 & -0.89217 & -0.37409 \\
\hline $\mathbf{1 0}$ & Grain yieed weight & -0.21728 & -0.00809 & 0.15126 & -0.18096 \\
\hline & plant & 0.09483 & -0.08482 & 0.38261 & -0.87857 \\
\hline
\end{tabular}

Table.2 Intra and inter cluster distances for ten characters in 40 ICRISAT sorghum genotypes

\begin{tabular}{|l|c|c|c|}
\hline & Cluster 1 & Cluster 2 & Cluster 3 \\
\hline Cluster 1 & 13.94 & 23.73 & 29.14 \\
\hline Cluster 2 & 23.73 & 10.67 & 24.99 \\
\hline Cluster 3 & 29.14 & 24.99 & 0.00 \\
\hline
\end{tabular}

Table.3 Cluster means for ten characters in 40 ICRISAT sorghum genotypes

\begin{tabular}{|c|c|c|c|c|c|c|c|c|c|c|}
\hline & $\begin{array}{c}\text { Plant } \\
\text { height }\end{array}$ & $\begin{array}{c}\text { Days to } \\
\mathbf{5 0 \%} \\
\text { flowering }\end{array}$ & $\begin{array}{c}\text { Days to } \\
\text { maturity }\end{array}$ & $\begin{array}{c}\text { No. of } \\
\text { leaves } \\
\text { per } \\
\text { plant }\end{array}$ & $\begin{array}{c}\text { Leaf } \\
\text { length }\end{array}$ & $\begin{array}{c}\text { Leaf } \\
\text { width }\end{array}$ & $\begin{array}{c}\text { Ear } \\
\text { length }\end{array}$ & $\begin{array}{c}\text { Straw } \\
\text { weight }\end{array}$ & $\begin{array}{c}\text { 100 } \\
\text { seed } \\
\text { weight }\end{array}$ & $\begin{array}{c}\text { Grain } \\
\text { yield } \\
\text { per } \\
\text { plant }\end{array}$ \\
\hline $\begin{array}{c}\text { Cluster } \\
\mathbf{1}\end{array}$ & 305.71 & 75.44 & 105.41 & 11.52 & 71.91 & 7.28 & 19.23 & 609.38 & 24.86 & 3.42 \\
\hline $\begin{array}{c}\text { Cluster } \\
\mathbf{2}\end{array}$ & 101.74 & 69.43 & 102.81 & 8.11 & 61.34 & 5.86 & 22.86 & 300.00 & 26.17 & 2.54 \\
\hline $\begin{array}{c}\text { Cluster } \\
\mathbf{3}\end{array}$ & 140.80 & 75.00 & 106.00 & 7.20 & 60.57 & 6.00 & 16.80 & 3000.00 & 24.80 & 2.28 \\
\hline
\end{tabular}


Table.4 Percent contribution of ten traits towards genetic divergence in 40 ICRISAT sorghum genotypes

\begin{tabular}{|c|c|c|}
\hline Source & $\begin{array}{c}\text { Times } \\
\text { ranked 1 }\end{array}$ & Contribution \% \\
\hline Plant height & 427 & 54.74 \\
\hline Days to 50\% flowering & 1 & 0.13 \\
\hline Days to maturity & 1 & 0.13 \\
\hline No. of leaves per plant & 2 & 0.26 \\
\hline Leaf length & 228 & 29.23 \\
\hline Leaf width & 0 & 0.00 \\
\hline Ear length & 9 & 1.15 \\
\hline Straw weight & 59 & 7.56 \\
\hline 100 seed weight & 7 & 0.90 \\
\hline Grain yield per plant & 46 & 5.90 \\
\hline
\end{tabular}

Fig.1 Principal component analysis diagram for 40 ICRISAT sorghum genotypes

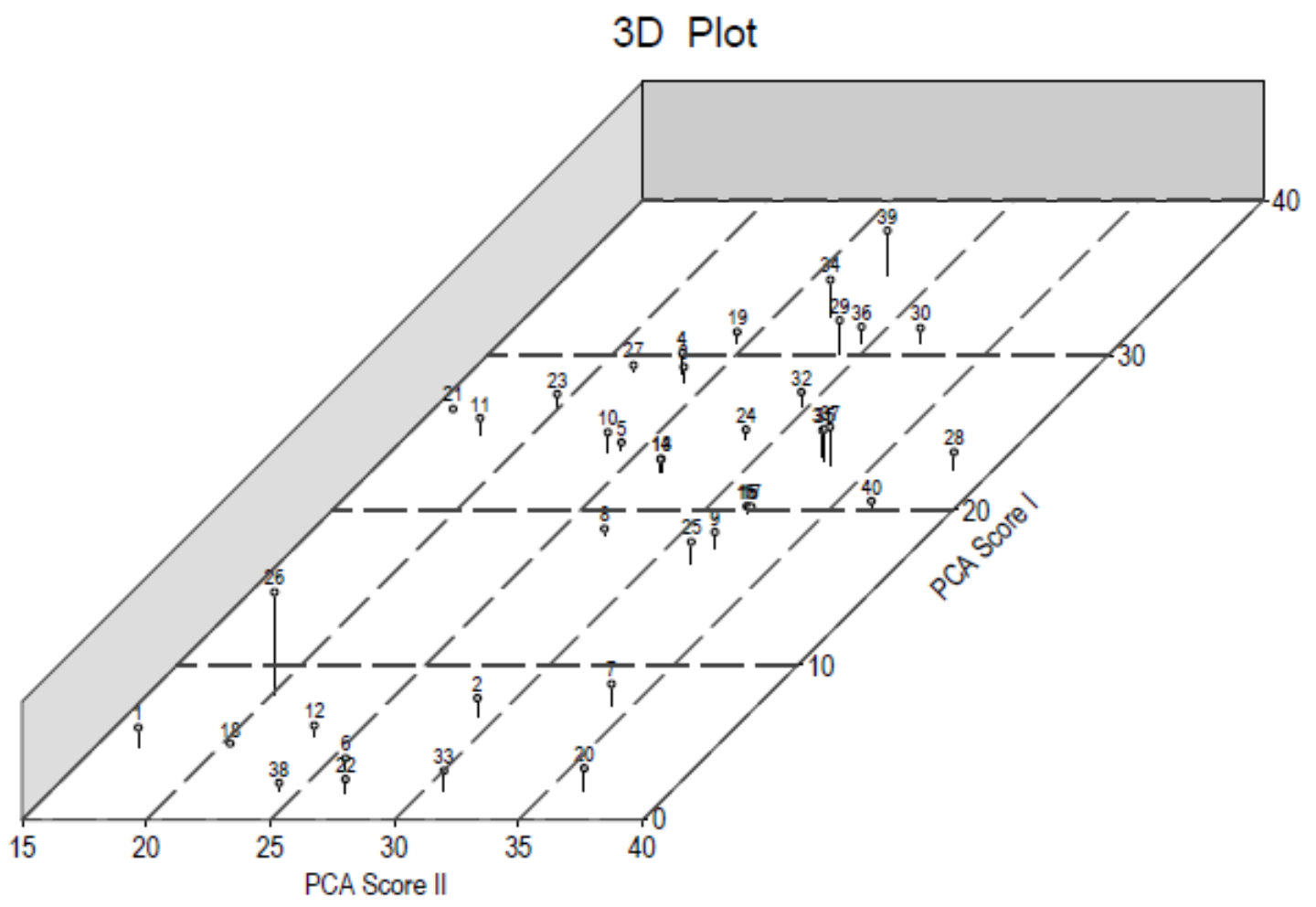


Table.5 Clustering pattern of 40 sorghum yellow pericarp genotypes

\begin{tabular}{|c|c|c|}
\hline Cluster & $\begin{array}{c}\text { No. of } \\
\text { accessions }\end{array}$ & Genotypes \\
\hline I & 32 & IS-14950, IS-22382, IS-18460, IS-2285, IS-22479, N-13, IS-19001, IS- \\
& & 3508, IS-3582, IS-14933, IS-22552, IS23053, IS-10934, IS-18395, IS- \\
& & 24698, IS-10918, IS-9868, IS-23457, N-14, IS-10306, IS-19128, IS- \\
& & 18398, IS-12503, IS-18415, IS-19247, IS-19238, IS-18348, IS-18328, \\
& & IS-22895, IS - 19479, IS-9893, IS-9892 \\
\hline II & 7 & IS-1134, IS-19106, IS-22399, IS-22415, IS-2267, IS - 11163, IS-19473 \\
\hline III & 1 & IS-12034 \\
\hline
\end{tabular}

Fig.2 Dendrogram showing clustering of 40 ICRISAT sorghum genotypes

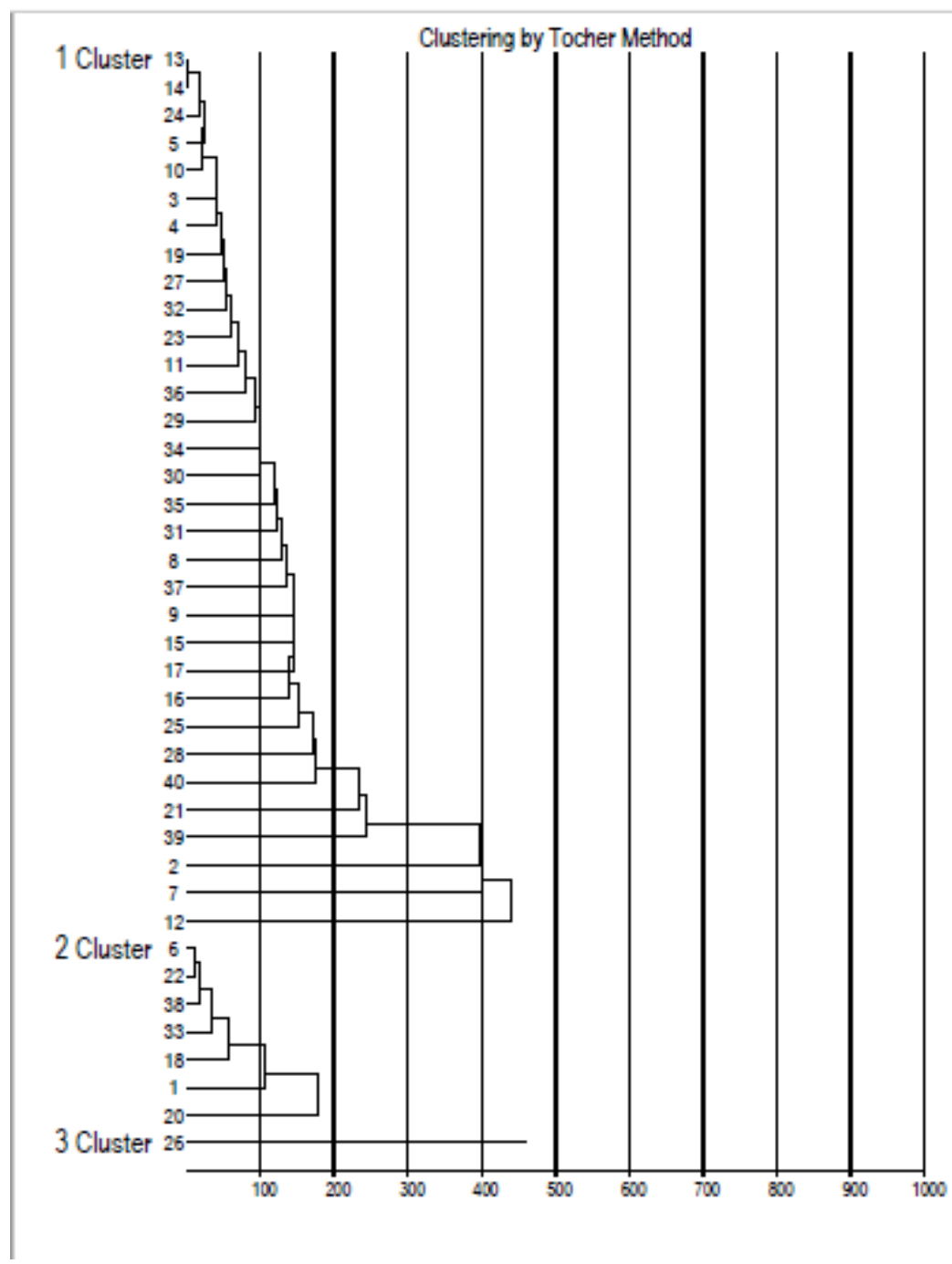




\section{Percent contribution to diversity}

Among all the traits studied in the present investigation, plant height contributed the maximum $(54.74 \%)$ towards genetic diversity (Table 4) followed by leaf length (29.23\%), straw weight $(7.56 \%)$ and 100 seed weight $(5.90 \%)$. Ear length $(1.15 \%)$, grain yield per plant $(0.90 \%)$, number of leaves per plant $(0.26 \%)$, days to $50 \%$ flowering and days to maturity $(0.13 \%)$ were the other traits contributing for genetic divergence.

The grouping of genotypes to different clusters is shown in Table 5. The genotypes belonging to wider inter cluster distance may be used for further sorghum breeding programmes. Similar results were reported by Yadav et al., (2004), Elangovan and Babu (2015), Damor et al., (2017) and Nishant et al., (2018).

\section{References}

Damor,H.I., Parmar, H.P. and Parmar, D.J. 2017. $\mathrm{D}^{2}$ analysis in forage Sorghum [Sorghum bicolor(L.) Moench] International Journal of Chemical Studies 2017; 5(4): 337-341
Elangovan M. and Babu P. K. (2015). Genetic variability and diversity of sorghum land race collected from Uttar Pradesh India. Indian Journal of plant genetic re-sources, 28(2):213 22

Ganesamurthy K, Punitha D, Elangovan M (2010) Genetic diversity among the land races of sorghum collected in Tamil Nadu. Electron J Plant Breed 1:1375-1379

Jain, S. K. and P. R. Patel (2016) Principal component and cluster analysis in sorghum (Sorghum bicolor (1.) Moench) Forage Res.,42 (2) : pp. 9095

Nishant Kumar Ahalawat, Vichitra Kumar Arya, Pradeep Kumar, and Shiv Kumar Singh, 2018. Genetic divergence in forage sorghum (Sorghum bicolor L. Moench) Journal of Applied and Natural Science 10 (1): $439-444$

Yadav, R., Grewal, R.P.S. and Pahuja, K.P. 2004. Multi-variate analyses in forage sorghum [Sorghum bicolor (L.) Moench]. The Indian Journal of Genetics and Plant Breeding, 64(1): 39-45.

\section{How to cite this article:}

Vara Prasad, B. V. and Sridhar, V. 2019. Diversity Studies in Yellow Pericarp Sorghum [Sorghum bicolor (L.) Moench] Genotypes for Yield Attributes. Int.J.Curr.Microbiol.App.Sci. 8(12): 361-366. doi: https://doi.org/10.20546/ijcmas.2019.812.048 